Article

\title{
Supply Chain Analysis of Cross Border Importing E-Commerce Considering with Bonded Warehouse and Direct Mailing
}

\author{
Yaqing $X u^{1}$, Hong Gui ${ }^{2}$, Jiang Zhang ${ }^{3}$ and Yihua Wei ${ }^{2, *}$ \\ 1 School of Economics and Management, Xidian University, Xi'an 710071, China; yaqingxu2002@sina.com \\ 2 School of Management, Shanghai University, Shanghai 200444, China; hgui@shu.edu.cn \\ 3 Robert B. Willumstad School of Business, Adelphi University, New York, NY 11530, USA; \\ zhang@adelphi.edu \\ * Correspondence: weiyh2001@aliyun.com
}

Received: 7 March 2019; Accepted: 25 March 2019; Published: 30 March 2019

\begin{abstract}
In this paper, we consider a cross-border supply chain system that has an import e-commerce company and an overseas supplier. We first considered a pure bonded warehouse mode in which the e-commerce company makes bulk purchase from an overseas supplier to a bonded warehouse and will deliver goods to customers from the bonded warehouse when customers order online. We constructed a Stackelberg model to obtain the equilibrium solution by using backward induction, and then properties of equilibrium strategy and equilibrium profit is discussed. We then studied the combined bonded warehouse and direct mailing mode in which the e-commerce company will purchase a single piece and mail to the customer directly if the bonded warehouse is out of stock. Analytical results demonstrate that the combined bonded warehouse and direct mailing mode may increase the profit of suppliers and decrease the profit of e-commerce companies.
\end{abstract}

Keywords: cross-border importing e-commerce; supply chain; bonded warehouse; direct mailing; Stackelberg model

\section{Introduction}

Cross-border e-commerce import in China has gradually emerged since 2013 and the amount of cross-border online shopping users has increased drastically. On August 1, 2014, the General Administration of Customs (GAC) of China announced "on the supervision of the import and export of goods and goods in cross-border trade in electronic commerce." The Chinese government has promulgated more than ten policies to encourage and standardize the import cross-border e-commerce, and the scale of the cross-border import e-commerce market has increased rapidly. Two policies in 2015, "on the related issues of the bonded import model for the pilot network purchase of e-commerce services in cross-border trade" by the General Administration of Customs and "reducing the import tariffs on consumer goods" by the China State Council, have fueled the cross-border import business growth. In the first half of 2017, the scale of cross-border e-commerce transactions in China reached 862.4 billion Chinese Yuan (about \$127 billion USD), a 66.3\% increase over the previous year [1].

Commonly, there are two main logistics modes in cross-border e-commerce: Bonded warehouse mode and direct mail mode. In the bonded warehouse mode, the e-commerce company purchases goods from overseas suppliers and transports them to bonded warehouses. When customers order online, the goods will be extracted from bonded warehouses. After the import goods clear the custom procedures, they will be sent to customers via local express delivery. In the direct mail mode, goods will be delivered directly from overseas procurement after customers order online. Bonded warehouse model has been the mainstream mode in contemporary import e-commerce. Many 
e-commerce companies are adopting bonded warehouse as their main method and using direct mail as a supplementary method. These companies include NetEase Kola shopping, Tmall International, Su Ninghai foreign purchase, jumei.com, Jingdong global purchase, Amazon overseas purchase, etc.

Our study attempts to answer the following questions: 1 . Can combined bonded warehouse and direct mail mode get more profits than the pure bonded warehouse mode? 2 . What are the supply chain decisions under the pure bonded warehouse mode and combined bonded warehouse and direct mail mode, respectively?; 3 . What are key decision-making problems for the cross-border e-commerce company?

There is a number of studies on cross-border e-commerce from various aspects. Chen and Yang (2017) [2] considered the impact of government policies on cross-border e-commerce providers in an empirical study. Wang et al. (2017) [3] utilized the transaction cost analysis to study the impact of cross-border e-commerce on China's international trade. Deng and Wang (2016) [4] used the panel data model to analyze the advantage of the cross-border e-commerce portal. Lu and Wang (2016) [5] and Wang et al. (2017) [6] studied the effects of the cross-border e-commerce comprehensive Pilot Area based on different modes. Lin et al. (2018) [7] conducted research on dysfunctional customer behavior in cross-border e-commerce. Zhang et al. (2017) [8] proposed a BP neural network model to assess credit risk in cross-border electricity providers.

In the area of logistics and supply chain of cross-border e-commerce research, Li and Miao (2017) [9] discussed the logistics status and operation mode of China's cross-border e-commerce. Maria et al. (2017) [10] summarized the role of cross-border B2C providers in logistics in greater China region. Kawa and Zrordka (2016) [11] proposed the concept of integrator to solve the logistics problem of cross-border e-commerce. Hsiao et al. (2017) [12] studied the feelings of customers and designed a logistics service of cross-border e-commerce by using Kansei Engineering. Feng et al. (2017) [13] adopted the L-COPRAS method to assess the strategic cost of the downstream supply chain of cross-border e-commerce.

Mikalef et al. $(2013,2014,2015)$ [14-16] empirically investigated alignment of internal resources with strategy and reviewed the literature on business-IT alignment from broad range of domains. They identified the antecedents such as procurement structure and organization size to show the positive impact of IT adoption on the supply chain improvement. They also used configuration theory approach to study the casual relationship of contingency elements between purchasing strategy and IT. While our work is focusing on cross-border e-commerce, the investment in technology of e-commerce and various factors such as government regulation and policies, tariff, and even politico environment all affect the supply chain performance. The alignment of the supply chain strategy with investment and resources is critical to the success of the e-commence company.

So far, although there have been many studies on cross-border e-commerce and the supply chain theory, there are few theoretical studies on cross-border e-commerce from the perspective of the supply chain model. Zhang and Cao (2017) [17] built a price competition model on cross-border e-commerce companies and regulators and traditional trade enterprises. Wang et al. (2017) [18] studied price competition between cross-border e-commerce companies and upstream suppliers that own both online and offline sales. However, their papers do not consider the features of the logistics mode in the cross-border e-commerce and cross-border e-commerce company's procurement decision.

In this paper, we consider a supply chain system consisting of an import cross-border e-commerce company and an overseas supplier. In this model, the overseas supplier first determines the bulk purchase price, and then the e-commerce company will make purchasing decisions according to the price. We consider both the pure bonded warehouse mode and combined bonded warehouse and direct mail mode.

\section{Assumptions and Notations}

$p$ : the retail price of import e-commerce company (including tax and postal charge);

$c_{0}$ : set-up cost of bonded warehouse mode; 
$c_{1}$ : unit logistics cost of bulk purchase to the bonded warehouse (including transportation fee and bonded warehouse storage costs, etc.);

$c_{2}$ : delivery fee per commodity from the bonded warehouse to the customer (including import tariff);

$c_{3}$ : delivery fee in the direct mail mode (including import tariff);

$w_{2}$ : purchase price per commodity in the direct mail mode, $C \leq w_{2} \leq p-c_{3}$;

$C$ : unit production cost of the overseas supplier;

$c_{r}$ : unit price of the overseas supplier in the direct mail mode;

$v$ : the salvage value of unsold commodities in the bonded warehouse, $v<C+c_{1}$;

$D$ : random continuous demand on interval $[0, \infty)$, with a probability density, $f(\cdot)$, and distribution function, $F(\cdot)$;

$w_{1}$ : bulk purchase price in the bonded warehouse mode, the overseas supplier's decision variable, where $C \leq w_{1} \leq p-c_{1}-c_{2}$;

$Q:$ bulk purchase quantity, the import cross-border e-commerce company's decision variable.

Without loss of generality, we utilize the following widely used assumption in supply chain, revenue management, queuing theory, and other models (Ziya et al., 2004 [19]; Wei et al., 2013 [20]).

Assumption 1. General failure rate function $e(x)=\frac{x f(x)}{1-F(x)}$ is strictly increasing.

\section{Mode 1: Pure Bonded Warehouse Mode}

In the pure bonded warehouse mode, the overseas supplier first decides the bulk purchase price, $w_{1}$, and then the e-commerce company makes a purchase decision with quantity, $Q$, according to $w_{1}$. We build the mathematical model to solve the problem using backward induction.

\subsection{The E-Commerce Company Decision}

The expected profit for the e-commerce company with purchase price $w_{1}$ and purchase quantity, $Q>0$, is

$$
\begin{aligned}
\pi_{r}\left(Q, w_{1}\right) & =\left(p-c_{2}\right) \cdot E \min (Q, D)+v \cdot E(Q-D)^{+}-\left(c_{0}+c_{1} Q+w_{1} Q\right) \\
& =\left(p-c_{2}-v\right) \cdot E \min (Q, D)-\left(c_{1}+w_{1}-v\right) Q-c_{0}
\end{aligned}
$$

where $y^{+}=\max \{y, 0\}$.

Similar to the newsvendor model, we can get

$$
\begin{gathered}
\frac{\partial \pi_{r}\left(Q, w_{1}\right)}{\partial Q}=\left(p-c_{2}-v\right)[1-F(Q)]-\left(c_{1}+w_{1}-v\right) \\
\frac{\partial^{2} \pi_{r}\left(Q, w_{1}\right)}{\partial Q^{2}}=-\left(p-c_{2}-v\right) f(Q)<0
\end{gathered}
$$

So $\pi_{r}\left(Q, w_{1}\right)$ is concave in $Q$, and let

$$
\frac{\partial \pi_{r}\left(Q, w_{1}\right)}{\partial Q}=\left(p-c_{2}-v\right)[1-F(Q)]-\left(c_{1}+w_{1}-v\right)=0
$$

According to formula (3), we can obtain the optimal purchase quantity,

$$
Q^{\prime}\left(w_{1}\right)=F^{-1}\left(\frac{p-c_{2}-c_{1}-w_{1}}{p-c_{2}-v}\right)
$$


Therefore, the expected profit of the e-commerce company becomes

$$
\begin{aligned}
\pi_{r}\left(w_{1}\right) & =\pi_{r}\left(Q^{\prime}\left(w_{1}\right), w_{1}\right) \\
& =\left(p-c_{2}-v\right) \cdot \operatorname{Emin}\left(Q^{\prime}\left(w_{1}\right), D\right)-\left(c_{1}+w_{1}-v\right) Q^{\prime}\left(w_{1}\right)-c_{0} \\
& =\left(p-c_{2}-v\right) \int_{0}^{Q^{\prime}\left(w_{1}\right)}[1-F(x)] d x-\left(c_{1}+w_{1}-v\right) Q^{\prime}\left(w_{1}\right)-c_{0}
\end{aligned}
$$

To avoid triviality, the optimal purchase quantity of the e-commerce company is $Q^{\prime}\left(w_{1}\right)$ only when $\pi_{r}\left(w_{1}\right)>c_{0}$, and the optimal purchase quantity is 0 when $\pi_{r}\left(w_{1}\right) \leq c_{0}$.

Theorem 1. (1) $Q^{\prime}\left(w_{1}\right)$ is a strictly decreasing function of $w_{1}$, and has the minimum value 0 when $w_{1}=$ $p-c_{2}-c_{1}$.

(2) $\pi_{r}\left(w_{1}\right)$ is a strictly decreasing function of $w_{1}$, and has the minimum value $-c_{0}$ when $w_{1}=p-c_{2}-c_{1}$.

Proof. (1) According to formula (3), we can obtain

$$
\frac{d Q^{\prime}\left(w_{1}\right)}{d w_{1}}=-\frac{1}{\left(p-c_{2}-v\right) f\left(Q^{\prime}\left(w_{1}\right)\right)}<0,
$$

So $Q^{\prime}\left(w_{1}\right)$ is a strictly decreasing function of $w_{1}$, and

$$
Q^{\prime}\left(p-c_{1}-c_{2}\right)=F^{-1}\left(\frac{0}{p-c_{2}-v}\right)=0
$$

(2) According to formula (4) we can obtain

$$
\frac{d \pi_{r}\left(w_{1}\right)}{d w_{1}}=\frac{\partial \pi_{r}\left(Q^{\prime}\left(w_{1}\right), w_{1}\right)}{\partial Q^{\prime}\left(w_{1}\right)} \cdot \frac{d Q^{\prime}\left(w_{1}\right)}{d w_{1}}+\frac{\partial \pi_{r}\left(Q^{\prime}\left(w_{1}\right), w_{1}\right)}{\partial w_{1}}=-Q^{\prime}\left(w_{1}\right)<0
$$

Therefore, $\pi_{r}\left(w_{1}\right)$ is a strictly decreasing in $w_{1}$, and

$$
\pi_{r}\left(p-c_{1}-c_{2}\right)=\pi_{r}\left(Q^{\prime}\left(p-c_{1}-c_{2}\right), p-c_{1}-c_{2}\right)=\pi_{r}\left(0, p-c_{1}-c_{2}\right)=-c_{0}
$$

The optimal purchase strategy of the e-commerce company can be given by the following proposition:

Proposition 1. (1) If $\pi_{r}(C) \leq 0$, the optimal decision for the e-commerce company is not to purchase;

(2) If $\pi_{r}(C)>0$, then there exists a $w_{1}^{\prime} \in\left(C, p-c_{1}-c_{2}\right)$, which makes $\pi_{r}\left(w_{1}^{\prime}\right)=0$. At this time, the optimal purchase quantity for the e-commerce company is:

$$
Q^{*}\left(w_{1}\right)= \begin{cases}Q^{\prime}\left(w_{1}\right) & w_{1}<w_{1}^{\prime} \\ 0 & w_{1} \geq w_{1}^{\prime}\end{cases}
$$

Proof. (1) According to Theorem $1, \pi_{r}\left(w_{1}\right)$ is a strictly decreasing function of $w_{1}$, so if $\pi_{r}(C) \leq 0$, then for any $w_{1}>C, \pi_{r}\left(w_{1}\right)$ is less than 0 , and the optimal decision of the e-commerce company is to make no purchase;

(2) Because $\pi_{r}\left(w_{1}\right)$ is a strictly decreasing function of $w_{1}$, and $\pi_{r}(C)>0, \pi_{r}\left(p-c_{1}-c_{2}\right)=-c_{0}<$ 0 , so there is definitely $w_{1}^{\prime} \in\left(C, p-c_{1}-c_{2}\right)$ to make $\pi_{r}\left(w_{1}^{\prime}\right)=0$, and $\pi_{r}\left(w_{1}\right)>0$ when $w_{1}<w_{1}^{\prime}$, 
meanwhile $\pi_{r}\left(w_{1}\right)<0$ when $w_{1}>w_{1}^{\prime}$. Thus, the optimal purchase quantity for the e-commerce company is

$$
Q^{*}\left(w_{1}\right)= \begin{cases}Q^{\prime}\left(w_{1}\right) & w_{1}<w_{1}^{\prime} \\ 0 & w_{1} \geq w_{1}^{\prime}\end{cases}
$$

\subsection{The Overseas Supplier Decision}

In this section, we discuss the bulk purchase price strategy of the overseas supplier in two situations base on the follower's decision, $Q^{*}\left(w_{1}\right)$.

(1) When $\pi_{r}(C) \leq 0$, regardless of the supplier's purchase price, the e-commerce company will not purchase, so both sides will have zero profit.

(2) When $\pi_{r}(C)>0$, then the decision for the supplier is to find $w_{1}$, that

$$
\max _{w_{1}} \pi_{s}\left(w_{1}\right)= \begin{cases}\left(w_{1}-C\right) \cdot Q^{\prime}\left(w_{1}\right) & C \leq w_{1}<w_{1}^{\prime} \\ 0 & w_{1}^{\prime} \leq w_{1} \leq p-c_{1}-c_{2}\end{cases}
$$

Denote $\phi\left(w_{1}\right)=\left(w_{1}-C\right) \cdot Q^{\prime}\left(w_{1}\right)$.

Theorem 2. (1) $\phi\left(w_{1}\right)$ is a strict concave in $w_{1}$, and there is a unique maximum point, $w_{1}^{*}$, in the interval of $\left[C, p-c_{1}-c_{2}\right]$;

(2) If $w_{1}^{*}<w_{1}^{\prime}$, then the optimal bulk price of the supplier is $w_{1}^{*}$, and the equilibrium strategy of both sides of the game is $\left(w_{1}^{*}, Q^{\prime}\left(w_{1}^{*}\right)\right)$; and if $w_{1}^{*}>w_{1}^{\prime}$, then the optimal bulk price of the supplier is less than but as close as possible to $w_{1}^{\prime}$ (denoted as $\left.w_{1}^{\prime-}\right)$, and the equilibrium strategy of the game is $\left(w_{1}^{\prime-}, Q^{\prime}\left(w_{1}^{\prime-}\right)\right)$.

Proof. (1) According to Assumption 1 and Proposition 5.1 (Ziya et al. 2004), it can be easily proved;

(2) Because of $\phi(C)=0$, the maximum point of $\pi_{s}\left(w_{1}\right)$ must be in interval $\left[C, w_{1}^{\prime}\right)$, at this time $\pi_{s}\left(w_{1}\right)=\phi\left(w_{1}\right)$. Because $\phi\left(w_{1}\right)$ is a strictly concave function of $w_{1}$, so if $w_{1} \leq w_{1}^{*}$, then $\phi\left(w_{1}\right)$ is strictly increased in $w_{1}$; else $\phi\left(w_{1}\right)$ is strictly decreased in $w_{1}$. So that:

If $w_{1}^{*}<w_{1}^{\prime}$, then $\pi_{s}\left(w_{1}\right)=\phi\left(w_{1}\right)$ takes the maximum point $w_{1}^{*}$ in interval $\left[C, w_{1}^{\prime}\right)$. And then the optimal bulk price of the supplier is $w_{1}^{*}$, and the equilibrium strategy of the game is $\left(w_{1}^{*}, Q^{\prime}\left(w_{1}^{*}\right)\right)$.

If $w_{1}^{*}>w_{1}^{\prime}$, because $\pi_{s}\left(w_{1}\right)=\phi\left(w_{1}\right)$ is nonnegative and strictly monotonically increasing in interval $\left[C, w_{1}^{\prime}\right)$, so that the optimal bulk price of the supplier is $w_{1}^{\prime-}$, and the equilibrium strategy of the game is $\left(w_{1}^{\prime-}, Q^{\prime}\left(w_{1}^{\prime-}\right)\right)$.

\section{Mode 2: Combined Bonded Warehouse and Direct Mail Mode}

In this mode, when the stock in the bonded warehouse is not enough to meet the demand, the e-commerce company can directly purchase commodities from the overseas supplier and deliver them by the direct mail mode.

\subsection{The E-Commerce Company Decision}

In the case that the bulk purchase price $w_{1}$ is given, we discuss in two situations:

a. If the e-commerce company does not choose bulk purchase, and all commodities are sold by direct mail, i.e., $Q=0$, then the expected profit is

$$
\Pi_{r}^{1}=\left(p-w_{2}-c_{3}\right) \cdot E D
$$


b. If the bulk purchase quantity $Q>0$, when the demand exceeds $Q$, the demand of beyond $Q$ will be met by direct mail mode, and then the expected profit is

$$
\begin{aligned}
& \Pi_{r}^{2}\left(Q, w_{1}\right) \\
= & \left(p-c_{2}\right) \cdot \operatorname{Emin}(Q, D)+v \cdot E(Q-D)^{+}+\left(p-w_{2}-c_{3}\right) E(D-Q)^{+}-\left(c_{1}+w_{1}\right) Q-c_{0} \\
= & \left(w_{2}+c_{3}-c_{2}-v\right) \cdot \operatorname{Emin}(Q, D)-\left(c_{1}+w_{1}-v\right) Q-c_{0}+\left(p-w_{2}-c_{3}\right) \cdot E D
\end{aligned}
$$

It can be shown that

$$
\frac{\partial \Pi_{r}^{2}\left(Q, w_{1}\right)}{\partial Q}=w_{2}+c_{3}-c_{2}-c_{1}-w_{1}-\left(w_{2}+c_{3}-c_{2}-v\right) F(Q)
$$

If $w_{1} \geq w_{2}+c_{3}-c_{2}-c_{1}$, then $\frac{\partial \Pi_{r}^{2}\left(Q, w_{1}\right)}{\partial Q} \leq 0$, and $\Pi_{r}^{2}\left(Q, w_{1}\right)$ is maximized when $Q=0$. Therefore,

$$
\Pi_{r}^{2}\left(0, w_{1}\right)=\left(p-w_{2}-c_{3}\right) \cdot E D-c_{0}<\Pi_{r}^{1}
$$

Accordingly, the optimal strategy of the e-commerce company is not to make a bulk purchase.

If $w_{1} \leq w_{2}+c_{3}-c_{2}-c_{1}$, then

$$
\frac{\partial^{2} \Pi_{r}^{2}\left(Q, w_{1}\right)}{\partial Q^{2}}=-\left(w_{2}+c_{3}-c_{2}-v\right) f(Q)<0
$$

So $\Pi_{r}^{2}\left(Q, w_{1}\right)$ is strictly concave in $Q$, and there is a unique maximum point

$$
Q^{\prime \prime}\left(w_{1}\right)=F^{-1}\left(\frac{w_{2}+c_{3}-c_{2}-c_{1}-w_{1}}{w_{2}+c_{3}-c_{2}-v}\right)
$$

The corresponding maximized expected profit is

$$
\begin{aligned}
& \Pi_{r}^{2}\left(w_{1}\right)=\Pi_{r}^{2}\left(Q^{\prime \prime}\left(w_{1}\right), w_{1}\right) \\
= & \left(w_{2}+c_{3}-c_{2}-v\right) \cdot E \operatorname{Emin}\left(Q^{\prime \prime}\left(w_{1}\right), D\right)-\left(c_{1}+w_{1}-v\right) Q^{\prime \prime}\left(w_{1}\right)-c_{0}+\left(p-w_{2}-c_{3}\right) \cdot E D \\
= & \left(w_{2}+c_{3}-c_{2}-v\right) \int_{0}^{Q^{\prime \prime}\left(w_{1}\right)}[1-F(x)] d x-\left(c_{1}+w_{1}-v\right) Q^{\prime \prime}\left(w_{1}\right)-c_{0}+\left(p-w_{2}-c_{3}\right) \cdot E D
\end{aligned}
$$

Let

$$
\psi\left(w_{1}\right)=\left(w_{2}+c_{3}-c_{2}-v\right) \int_{0}^{Q^{\prime \prime}\left(w_{1}\right)}[1-F(x)] d x-\left(c_{1}+w_{1}-v\right) Q^{\prime \prime}\left(w_{1}\right)-c_{0}
$$

represents the difference of the e-commerce company between the maximum profit for bulk purchase and not bulk purchase. According to (8), (14), if $\psi\left(w_{1}\right) \leq 0$, then the optimal strategy of the e-commerce company is not to bulk purchase, and if $\psi\left(w_{1}\right)>0$, then the optimal purchase quantity of e-commerce company is $Q^{\prime \prime}\left(w_{1}\right)$.

Proposition 2. (1) $Q^{\prime \prime}\left(w_{1}\right)<Q^{\prime}\left(w_{1}\right)$, i.e., given the same bulk purchase price, the bulk purchase quantity of the e-commerce company in mode 2 is less than that in mode 1 ;

(2) $\psi\left(w_{1}\right)<\pi_{r}\left(w_{1}\right)$, i.e., given the same bulk purchase price, the profit difference for bulk purchase and not bulk purchase in mode 2 is less than that in mode 1.

Proof. (1) Given that $w_{2}+c_{3} \leq p$,

$$
Q^{\prime \prime}\left(w_{1}\right)=F^{-1}\left(1-\frac{c_{1}+w_{1}-v}{w_{2}+c_{3}-c_{2}-v}\right) \leq F^{-1}\left(1-\frac{c_{1}+w_{1}-v}{p-c_{2}-v}\right)=Q^{\prime}\left(w_{1}\right)
$$


(2) Similarly, we have

$$
\begin{aligned}
\psi\left(w_{1}\right) & =\left(w_{2}+c_{3}-c_{2}-v\right) \int_{0}^{Q^{\prime \prime}\left(w_{1}\right)}[1-F(x)] d x-\left(c_{1}+w_{1}-v\right) Q^{\prime \prime}\left(w_{1}\right)-c_{0} \\
& \leq\left(p-c_{2}-v\right) \int_{0}^{Q^{\prime \prime}\left(w_{1}\right)}[1-F(x)] d x-\left(c_{1}+w_{1}-v\right) Q^{\prime \prime}\left(w_{1}\right) \\
& \leq\left(p-c_{2}-v\right) \int_{0}^{Q^{\prime}\left(w_{1}\right)}[1-F(x)] d x-\left(c_{1}+w_{1}-v\right) Q^{\prime}\left(w_{1}\right)=\pi_{r}\left(w_{1}\right)
\end{aligned}
$$

The proposition is proved.

Combine all the analysis above, we can obtain

Theorem 3. (1) The purchase quantity $Q^{\prime \prime}\left(w_{1}\right)$ is strictly decreasing in purchase price $w_{1}$, and has the minimum value 0 when $w_{1}=w_{2}+c_{3}-c_{2}-c_{1}$;

(2) $\psi\left(w_{1}\right)$ is strictly decreasing in purchase price $w_{1}$, and has the minimum value $-c_{0}$ when $w_{1}=$ $w_{2}+c_{3}-c_{2}-c_{1}$.

Proof. Similar to the proof of Theorem 1.

Proposition 3. (1) If $\psi(C) \leq 0$ or $w_{1} \geq w_{2}+c_{3}-c_{2}-c_{1}$, then the e-commerce company will not bulk purchase;

(2) If $\psi(C)>0$ and $w_{1} \leq w_{2}+c_{3}-c_{2}-c_{1}$, then there exists $w_{1}^{\prime \prime} \in\left(C, w_{2}+c_{3}-c_{2}-c_{1}\right)$ such that $\psi\left(w_{1}^{\prime \prime}\right)=0$ and the optimal purchase quantity for the e-commerce company is

$$
Q^{* *}\left(w_{1}\right)= \begin{cases}Q^{\prime \prime}\left(w_{1}\right) & w_{1}<w_{1}^{\prime \prime} \\ 0 & w_{1} \geq w_{1}^{\prime \prime}\end{cases}
$$

Proof. Similar to the proof of Proposition 1.

\subsection{The Overseas Supplier Decision}

We proceed our discussion in the following two cases:

(1) If $\psi(C) \leq 0$, then the e-commerce company will not bulk purchase, and all the demand will be met by the direct mail mode, in which the expected profit for the supplier is

$$
\Pi_{\mathrm{s}}^{1}=\left(w_{2}-C-c_{r}\right) \cdot E D
$$

(2) If $\psi(C)>0$, according to Proposition 3, the expected profit for the supplier is

$$
\Pi_{\mathrm{s}}^{2}\left(w_{1}\right)= \begin{cases}\left(w_{1}-C\right) Q^{\prime \prime}\left(w_{1}\right)+\left(w_{2}-C-c_{r}\right) E\left[D-\min \left(D, Q^{\prime \prime}\left(w_{1}\right)\right)\right] & C \leq w_{1}<w_{1}^{\prime \prime} \\ \left(w_{2}-C-c_{r}\right) \cdot E D & w_{1}^{\prime \prime} \leq w_{1} \leq p-c_{1}-c_{2}\end{cases}
$$

Denote $\Phi\left(w_{1}\right)=\left(w_{1}-C\right) Q^{\prime \prime}\left(w_{1}\right)-\left(w_{2}-C-c_{r}\right) \operatorname{Emin}\left(D, Q^{\prime \prime}\left(w_{1}\right)\right)$.

Theorem 4. (1) $\Phi\left(w_{1}\right)$ is a strict concave function in $w_{1}$, and there is a unique maximum, $w_{1}^{* *}$, in the interval of $\left[C, w_{2}+c_{3}-c_{2}-c_{1}\right]$;

(2) If $w_{1}^{* *}<w_{1}^{\prime \prime}$, then the optimal bulk price for the supplier is $w_{1}^{* *}$, and the equilibrium strategy of the game is $\left(w_{1}^{* *}, Q^{\prime \prime}\left(w_{1}^{* *}\right)\right)$; if $w_{1}^{* *}>w_{1}^{\prime \prime}$, then the optimal bulk price is less than but as close as possible to $w_{1}^{\prime \prime}$ (denoted as $\left.w_{1}^{\prime \prime}\right)$, and the equilibrium strategy of the game is $\left(w_{1}^{\prime \prime}, Q^{\prime \prime}\left(w_{1}^{\prime \prime}\right)\right.$ ).

Proof. Similar to the proof of Theorem 3. 
A numerical example is presented in the next section to demonstrate our results and some interesting managerial insights are also provided.

\section{Numerical Analysis}

Consider an e-commerce company to import some commodities abroad to sell in the domestic market. The retail price $p$ of the commodity is four thousand USD/ unit, the residual value $v$ of unsold commodities is 0.6 thousand USD/ unit, the set-up $\operatorname{cost} c_{0}$ in bonded warehouse mode is 0.5 thousand USD, the bulk purchase logistics $\operatorname{cost} c_{1}$ is 0.3 thousand USD/unit, the delivery fee $c_{2}$ from the bonded warehouse to the customer (import tax included) is 0.6 thousand USD/unit, the delivery fee $c_{3}$ in the direct mail mode (import tax included) is 1.1 thousand USD/unit, the unit production $\operatorname{cost} C$ of the overseas supplier is 1 thousand USD/unit, the unit purchase price $w_{2}$ is equal to the overseas retail price 2.8 thousand USD/unit, and the unit retail fee $c_{r}$ of the overseas supplier in the direct mail mode is 0.6 thousand USD. The demand follows a truncated normal distribution with a mean value of 10 and a standard deviation of 4 , i.e.,

$$
F(x)=\frac{1}{A} \int_{0}^{x} \frac{1}{\sqrt{2 \pi} \sigma} e^{-\frac{(x-\mu)^{2}}{2 \sigma^{2}}} d x
$$

in which,

$$
A=\int_{0}^{\infty} \frac{1}{\sqrt{2 \pi} \sigma} e^{-\frac{(x-\mu)^{2}}{2 \sigma^{2}}} d x, \mu=10, \sigma=4
$$

\subsection{Comparison of Mode 1 and Mode 2}

Intuitively, the e-commerce company can sell more commodities and bring more profit in the combined bonded warehouse and direct mail mode than that in the pure bonded warehouse mode. But the results of Table 1 show that the retailer's expected profit will indeed increase from 2.39 thousand USD to 2.77 thousand USD if the bulk price of the supplier is unchanged in the combined bonded warehouse and direct mail mode, comparing with the pure bonded warehouse mode. However, if the supplier adjusts its bulk price from 2.48 USD to 2.72 USD, the expected profit of the e-commerce company will drop from 2.39 USD to 1.38 thousand USD in equilibrium. In other words, the increase of the direct mail mode on the basis of the bonded warehouses increases the expected profit of the supplier and the total supply chain profit, but reduces the expected profit of the e-commerce company.

Table 1. Comparison of mode 1 and mode 2.

\begin{tabular}{ccccc}
\hline & Bulk Price & $\begin{array}{c}\text { Purchase } \\
\text { Quantity of the } \\
\text { E-Commerce } \\
\text { Company }\end{array}$ & $\begin{array}{c}\text { Expected Profit } \\
\text { of the Supplier }\end{array}$ & $\begin{array}{c}\text { Expected Profit } \\
\text { of the } \\
\text { E-Commerce } \\
\text { Company }\end{array}$ \\
\hline $\begin{array}{c}\text { Total Expected } \\
\text { Profit of the } \\
\text { Supply Chain } \\
\text { results of mode 1 }\end{array}$ & 2.48 & 7.00 & 10.35 & 2.39 \\
\hline $\begin{array}{c}\text { Results of mode 2 } \\
\text { use the } \\
\text { equilibrium bulk } \\
\text { price of mode 1 }\end{array}$ & 2.48 & 6.60 & 14.45 & 2.77 \\
\hline $\begin{array}{c}\text { Equilibrium } \\
\text { results of mode } 2\end{array}$ & 2.72 & 5.08 & 14.97 & 1.38 \\
\hline
\end{tabular}

\subsection{Influence of Mean Value of Demand $\mu$}

Tables 2 and 3 show respectively the equilibrium results of mode 1 and mode 2 where the mean value of demand is $\{6,7,8,9,10,11,12,13$, and 14$\}$. In the two modes, the equilibrium price, the equilibrium purchase quantity, and the equilibrium expected profit of the supplier and the e-commerce company all increase with the increase of the mean value of demand. And for each mean value of 
demand, the equilibrium price, the equilibrium expected profit of the supplier and the total expected profit of the supply chain in the combined bonded warehouse and direct mail mode are greater than those in the pure bonded warehouse mode; the equilibrium purchase quantity and the equilibrium expected profit of e-commerce company in the combined bonded warehouse and direct mail mode are less than those in the pure bonded warehouse mode.

Table 2. Influence of mean value of demand $\mu$ on mode 1.

\begin{tabular}{cccccc}
\hline $\begin{array}{c}\text { Mean Value } \\
\text { of Demand }\end{array}$ & $\begin{array}{c}\text { Equilibrium } \\
\text { Price }\end{array}$ & $\begin{array}{c}\text { Equilibrium } \\
\text { Purchase } \\
\text { Quantity }\end{array}$ & $\begin{array}{c}\text { Equilibrium } \\
\text { Expected Profit } \\
\text { of the Supplier }\end{array}$ & $\begin{array}{c}\text { Equilibrium Expected } \\
\text { Profit of the } \\
\text { E-Commerce Company }\end{array}$ & $\begin{array}{c}\text { Total Expected } \\
\text { Profit of the } \\
\text { Supply Chain }\end{array}$ \\
\hline 6 & 2.25 & 4.46 & 5.57 & 0.98 & 6.55 \\
\hline 7 & 2.30 & 5.07 & 6.59 & 1.46 & 8.05 \\
\hline 8 & 2.36 & 5.68 & 7.73 & 1.85 & 9.57 \\
\hline 9 & 2.42 & 6.33 & 8.99 & 2.16 & 11.15 \\
\hline 10 & 2.48 & 7.00 & 10.35 & 2.39 & 12.75 \\
\hline 11 & 2.53 & 7.72 & 11.81 & 2.61 & 14.42 \\
\hline 12 & 2.58 & 8.44 & 13.34 & 2.75 & 16.08 \\
\hline 13 & 2.63 & 9.16 & 14.93 & 2.80 & 17.73 \\
\hline 14 & 2.66 & 9.98 & 16.56 & 2.97 & 19.53 \\
\hline
\end{tabular}

Table 3. Influence of mean value of demand $\mu$ on mode 2.

\begin{tabular}{cccccc}
\hline $\begin{array}{c}\text { Mean Value } \\
\text { of Demand }\end{array}$ & $\begin{array}{c}\text { Equilibrium } \\
\text { Price }\end{array}$ & $\begin{array}{c}\text { Equilibrium } \\
\text { Purchase } \\
\text { Quantity }\end{array}$ & $\begin{array}{c}\text { Equilibrium } \\
\text { Expected Profit } \\
\text { of the Supplier }\end{array}$ & $\begin{array}{c}\text { Equilibrium Expected } \\
\text { Profit of the } \\
\text { E-Commerce Company }\end{array}$ & $\begin{array}{c}\text { Total Expected } \\
\text { Profit of the } \\
\text { Supply Chain }\end{array}$ \\
\hline 6 & 2.45 & 3.39 & 9.31 & 0.67 & 9.98 \\
\hline 7 & 2.58 & 3.48 & 10.58 & 0.75 & 11.32 \\
\hline 8 & 2.65 & 3.84 & 11.93 & 0.92 & 12.85 \\
\hline 9 & 2.68 & 4.48 & 13.40 & 1.19 & 14.59 \\
\hline 10 & 2.72 & 5.08 & 14.97 & 1.38 & 16.35 \\
\hline 11 & 2.75 & 5.76 & 16.62 & 1.57 & 18.20 \\
\hline 12 & 2.78 & 6.45 & 18.34 & 1.72 & 20.06 \\
\hline 13 & 2.80 & 7.23 & 20.11 & 1.89 & 22.00 \\
\hline 14 & 2.80 & 8.22 & 21.90 & 2.19 & 24.08 \\
\hline
\end{tabular}

\subsection{Influence of Standard Deviation of Demand $\sigma$}

Tables 4 and 5 show respectively the equilibrium results in two modes in which the standard deviation of demand is $\{3,3.5,4,4.5,5,5.5,6,6.5,7\}$. The greater the standard deviation of demand, the greater the fluctuation of demand. In the pure bonded warehouse mode, the equilibrium price, the equilibrium expected profit of the supplier and the total expected profit of the supply chain decrease with the increase of demand fluctuation; the equilibrium purchase quantity decreases first and then increases with the increase of demand fluctuation, and the equilibrium profit of the e-commerce company increases first and then decreases with the increase of demand fluctuation.

In the combined bonded warehouse and direct mail mode, the equilibrium price decreases with the increase of demand fluctuation; the equilibrium purchase quantity, the equilibrium expected profit of the supplier and the total expected profit of the supply chain decrease first and then increase with the increase of demand fluctuation; and the equilibrium expected profit of the e-commerce company increases first and then decreases with the increase of demand fluctuation. 
Table 4. Influence of standard deviation of demand $\sigma$ on mode 1.

\begin{tabular}{cccccc}
\hline $\begin{array}{c}\text { Standard } \\
\text { Deviation of } \\
\text { Demand. }\end{array}$ & $\begin{array}{c}\text { Equilibrium } \\
\text { Price }\end{array}$ & $\begin{array}{c}\text { Equilibrium } \\
\text { Purchase } \\
\text { Quantity }\end{array}$ & $\begin{array}{c}\text { Equilibrium } \\
\text { Expected Profit } \\
\text { of the Supplier }\end{array}$ & $\begin{array}{c}\text { Equilibrium Expected } \\
\text { Profit of the } \\
\text { E-Commerce Company }\end{array}$ & $\begin{array}{c}\text { Total Expected } \\
\text { Profit of the } \\
\text { Supply Chain }\end{array}$ \\
\hline 3.0 & 2.64 & 7.07 & 11.60 & 2.02 & 13.62 \\
\hline 3.5 & 2.56 & 6.9 & 10.90 & 2.22 & 13.12 \\
\hline 4.0 & 2.48 & 7.00 & 10.35 & 2.39 & 12.75 \\
\hline 4.5 & 2.42 & 7.00 & 9.95 & 2.41 & 12.36 \\
\hline 5.0 & 2.36 & 7.10 & 9.66 & 2.43 & 12.09 \\
\hline 5.5 & 2.32 & 7.17 & 9.47 & 2.33 & 11.79 \\
\hline 6.0 & 2.28 & 7.30 & 9.35 & 2.23 & 11.58 \\
\hline 6.5 & 2.25 & 7.44 & 9.30 & 2.08 & 11.38 \\
\hline 7.0 & 2.23 & 7.56 & 9.29 & 1.88 & 11.17 \\
\hline
\end{tabular}

Table 5. Influence of standard deviation of demand $\sigma$ on mode 2.

\begin{tabular}{cccccc}
\hline $\begin{array}{c}\text { Standard } \\
\text { Deviation of } \\
\text { Demand }\end{array}$ & $\begin{array}{c}\text { Equilibrium } \\
\text { Price }\end{array}$ & $\begin{array}{c}\text { Equilibrium } \\
\text { Purchase } \\
\text { Quantity }\end{array}$ & $\begin{array}{c}\text { Equilibrium } \\
\text { Expected Profit } \\
\text { of the Supplier }\end{array}$ & $\begin{array}{c}\text { Equilibrium Expected } \\
\text { Profit of the } \\
\text { E-Commerce Company }\end{array}$ & $\begin{array}{c}\text { Total Expected } \\
\text { Profit of the } \\
\text { Supply Chain }\end{array}$ \\
\hline 3.0 & 2.80 & 5.67 & 15.53 & 1.37 & 16.89 \\
\hline 3.5 & 2.76 & 5.33 & 15.19 & 1.39 & 16.57 \\
\hline 4.0 & 2.72 & 5.08 & 14.97 & 1.38 & 16.35 \\
\hline 4.5 & 2.68 & 4.93 & 14.88 & 1.36 & 16.24 \\
\hline 5.0 & 2.65 & 4.81 & 14.91 & 1.28 & 16.19 \\
\hline 5.5 & 2.62 & 4.76 & 15.03 & 1.20 & 16.24 \\
\hline 6.0 & 2.59 & 4.79 & 15.24 & 1.12 & 16.37 \\
\hline 6.5 & 2.55 & 4.94 & 15.51 & 1.09 & 16.60 \\
\hline 7.0 & 2.49 & 5.30 & 15.82 & 1.13 & 16.94 \\
\hline
\end{tabular}

\section{Conclusions}

This paper discusses an import cross-border e-commerce supply chain system consisting of a retail e-commerce company and an overseas supplier, both the pure bonded warehouse mode (mode 1) and combined bonded warehouse and direct mail mode (mode 2) are discussed respectively.

In mode 1 , we obtain two critical purchase prices, $w_{1}^{*}$ and $w_{1}^{\prime}$. If $w_{1}^{*}<w_{1}^{\prime}$, then the equilibrium bulk price of the supplier is $w_{1}^{*}$ with the equilibrium purchase quantity of the e-commerce company $Q^{\prime}\left(w_{1}^{*}\right)$; otherwise the equilibrium bulk price of the supplier is $w_{1}^{\prime-}$ with the equilibrium purchase quantity of the e-commerce company $Q^{\prime}\left(w_{1}^{\prime-}\right)$.

In mode 2, we obtain two critical purchase prices $w_{1}^{* *}$ and $w_{1}^{\prime \prime}$. If $w_{1}^{* *}<w_{1}^{\prime \prime}$, then the equilibrium bulk price of the supplier is $w_{1}^{* *}$ with the equilibrium purchase quantity of the e-commerce company is $Q^{\prime \prime}\left(w_{1}^{* *}\right)$; otherwise the equilibrium bulk price of the supplier is $w_{1}^{\prime \prime}-$ with the equilibrium purchase quantity of the e-commerce company $Q^{\prime \prime}\left(w_{1}^{\prime \prime}-\right)$.

Our numerical results show that: (i) Adding direct mail to the bonded warehouse mode will increase the equilibrium profit of the supplier and the total supply chain, but will reduce the equilibrium profit of the e-commerce company, this means that mode 2 will be detrimental to cross-border e-commerce companies if there is no profit redistribution agreement with suppliers; (ii) for both modes, the equilibrium price, the equilibrium purchase quantity, and the equilibrium expected profit of the supplier and the e-commerce company are all increasing when the mean value of demand increases; (iii) in mode 1, when the variance of the demand increases, the equilibrium price, the equilibrium expected profit of the supplier and the total expected profit of the supply chain decrease, but the equilibrium purchase quantity first decreases and then increases, and the equilibrium profit of 
the e-commerce company increases first and then decreases; (iv) in mode 2, when the variance of the demand increases, the equilibrium price decreases, the equilibrium purchase quantity, the equilibrium expected profit of the supplier and the total expected profit of the supply chain first decrease and then increase, and the equilibrium expected profit of the e-commerce company first increases and then decreases.

This research could be further extended to the following two cases: (i) We consider that the domestic retail price $p$ and the unit purchase price $w_{2}$ (overseas retail price) are uncontrollable. In further research we could consider $p$ as the decision variable for the e-commerce company and $w_{2}$ as the decision variable for the supplier. (ii) One may consider the impact of changes in import e-commerce policies (such as import tariff, bonded warehouse, etc.) on the supply chain.

Author Contributions: The paper is written by Y.W. and Y.X., and finally revised and checked by Y.X., H.G. and J.Z. All authors read and approved the final manuscript.

Funding: This research was funded by the National Natural Science Foundation of China (No. 71771184), the China Education Ministry Humanities and Social Science Research Fund Project (16XJA630003), the Humanities and Social Science Talent Plan of Shaanxi Province (No. 91704160004).

Conflicts of Interest: The authors declare no conflict of interest.

\section{References}

1. China e-Commerce Research Center, Mobdata: 2017 Cross-Border e-Commerce in China Research Report. Available online: http:/ / www.100ec.cn/zt/17kjdsbg/ (accessed on 7 March 2018). (In Chinese)

2. Chen, N.; Yang, J. Mechanism of government policies in cross-border e-commerce on firm performance and implications on m-commerce. Int. J. Mob. Commun. 2017, 15, 69-84. [CrossRef]

3. Wang, Y.; Wang, Y.; Lee, S.H. The effect of cross-border e-commerce on china's international trade: An empirical study based on transaction cost analysis. Sustainability 2017, 9, 2028. [CrossRef]

4. Deng, Z.; Wang, Z. Early-mover advantages at cross-border business-to-business e-commerce portals. J. Bus. Res. 2016, 69, 6002-6011. [CrossRef]

5. Lu, B.; Wang, H. Research on the competitive strategy of cross-border e-commerce comprehensive pilot area based on the spatial competition. Sci. Program. 2016, 2016, 12. [CrossRef]

6. Wang, H.; Xiao, M.; Huo, Y. Research on the construction strategy of cross-border e-commerce comprehensive pilot area based on salop model. Int. J. Innov. Comput. Inf. Control 2017, 13, 1563-1577.

7. Lin, A.J.; Li, E.Y.; Lee, S.Y. Dysfunctional customer behavior in cross-border e-commerce: A justice-affectbehavior model. J. Electron. Commer. Res. 2018, 19, 36-54.

8. Zhang, X.; Zhao, X.; Wu, N. Credit risk assessment model for cross-border e-commerce in a BP neural network based on Pso-Ga. Agro Food Ind. Hi-Tech 2017, 28, 411-414.

9. Li, H.; Miao, X. Research on the status quo and operation model of logistics of cross-border e-commerce in china. Agro Food Ind. Hi-Tech 2017, 28, 2845-2849.

10. Maria, G.; Riccardo, M.; Alessandro, P.; Angela, T. Cross-border b2c e-commerce to greater China and the role of logistics: A literature review. Int. J. Phys. Distrib. Logist. Manag. 2017, 47, 772-795.

11. Kawa, A.; Zdrenka, W. Conception of integrator in cross-border e-commerce. LogForum 2016, 12, 63-73. [CrossRef]

12. Hsiao, Y.H.; Chen, M.C.; Liao, W.C. Logistics service design for goss-border e-commerce using kansei engineering with textmining-based online content analysis. Telemat. Inform. 2017, 34, 284-302. [CrossRef]

13. Feng, L.; Ma, J.; Wang, Y.; Yang, J. Supply chain downstream strategic cost evaluation using L-COPRAS method in cross-border E-commerce. Int. J. Comput. Intell. Syst. 2017, 10, 815-823. [CrossRef]

14. Mikalef, P.; Pateli, A.; Batenburg, R.; van de Wetering, R. Investigating the impact of procurement alignment on supply chain management performance. Procedia Technol. 2013, 9, 310-319. [CrossRef]

15. Mikalef, P.; Pateli, A.; Batenburg, R.; van de Wetering, R. Business alignment in the procurement domain: A study of antecedents and determinants of supply chain performance. Int. J. Inf. Syst. Proj. Manag. 2014, 2, 43-59.

16. Mikalef, P.; Pateli, A.; Batenburg, R.S.; van de Wetering, R. Purchasing alignment under multiple contingencies: A configuration theory approach. Ind. Manag. Data Syst. 2015, 115, 625-645. [CrossRef] 
17. Zhang, X.; Cao, G. Stocking and pricing strategy of import cross-border e-commerce based on bertrand model. Soft Sci. 2017, 31, 130-135. (In Chinese)

18. Wang, X.; Sun, Z.; Zhan, H. Impact of a dual channel supply chain in cross-border e-commerce with different power structures. J. Syst. Eng. 2017, 32, 385-396. (In Chinese)

19. Ziya, S.; Ayhan, H.; Foley, R.D. Relationships among three assumption in revenue management. Oper. Res. 2004, 52, 804-809. [CrossRef]

20. Wei, Y.; Xu, C.; Hu, Q. Transformation of optimization problems in revenue management, queueing system, and supply chain management. Int. J. Prod. Econ. 2013, 146, 588-597. [CrossRef]

(C) 2019 by the authors. Licensee MDPI, Basel, Switzerland. This article is an open access article distributed under the terms and conditions of the Creative Commons Attribution (CC BY) license (http:/ / creativecommons.org/licenses/by/4.0/). 